\title{
COVID-19 in adult acute myeloid leukemia patients: a long- term follow-up study from the European Hematology Association survey (EPICOVIDEHA)
}

\section{Francesco Marchesi}

IRCCS Regina Elena National Cancer Institute https://orcid.org/0000-0001-6353-2272

Jon Salmanton-Garcia ( $\sim$ jon.salmanton-garcia@uk-koeln.de)

University Hospital Cologne https://orcid.org/0000-0002-6766-8297

\section{Ziad EMARAH}

Oncology Center, Mansoura University

\section{Klára PIUKOVICS}

Department of Internal Medicine, South Division Faculty of Medicine University of Szeged

\section{Marcio Nucci}

Hospital Universitário, Universidade Federal do Rio de Janeiro

\section{Alberto Lopez-Garcia}

Health Research Institute IIS-FJD, Fundacion Jimenez Diaz University Hospital https://orcid.org/0000-0002-5354-5261

\section{Zdenek Racil}

Charles University

\section{Francesca Farina}

IRCCS San Raffaele Institute

\section{Marina POPOVA}

RM Gorbacheva Research Institute, Pavlov University

\section{Sofia ZOMPI}

Stem Cell Transplant Center, AOU Citta' della Salute e della Scienza

\section{Ernesta Audisio}

Ospedale Civile "Molinette"

Marie-Pierre Ledoux

CHU Strasbourg

\section{Luisa VERGA}

Azienda Ospedaliera San Gerardo - Monza

\section{Barbora Weinbergerova}

Masaryk University and University Hospital Brno

\section{Tomas Szotkowski}

Palacky University Olomouc and University Hospital Olomouc

\section{Maria Silva}

IPOFG

\section{Nicola Stefano Fracchiolla}

U.O. di Ematologia - Centro Trapianti di Midollo, Università degli Studi di Milano

Nick DE JONGE

Amsterdam UMC, location VUmc

\section{Graham Collins}

Oxford University Hospital 


\section{Monia Marchetti}

Azienda Ospedaliera SS Antonio e Biagio e Cesare Arrigo https://orcid.org/0000-0001-7615-0572

\section{Gabriele MAGLIANO}

ASST Grande Ospedale Metropolitano Niguarda

\section{Carolina GARCIA-VIDAL}

Department of Infectious Diseases, Hospital Clinic de Barcelona, University of Barcelona, IDIBAPS

\section{Monika M. BIERNAT}

Department of Haematology, Blood Neoplasms, and Bone Marrow Transplantation, Wroclaw Medical University

Jaap van Doesum

Universitair medisch centrum Groningen https://orcid.org/0000-0003-0214-3219

Marina MACHADO

Clinical Microbiology and Infectious Diseases Department, Hospital General Universitario Gregorio Marañón

\section{Fatih Demirkan}

Dokuz Eylul University

\section{Murtadha Al Khabori}

Sultan Qaboos University Hospital https://orcid.org/0000-0002-2937-8838

\section{Pavel Zak}

Charles University and University Hospital Hradec Králové

\section{Benjamin Visek}

Charles University, University Hospital Hradec Kralove

\section{Igor STOMA}

Gomel State Medical University

\section{Gustavo-Adolfo MÉNDEZ}

Hospital Escuela de Agudos Dr. Ramón Madariaga

\section{Johan Maertens}

University Hospital Gasthuisberg https://orcid.org/0000-0003-4257-5980

\section{Nina KHANNA}

Division of Infectious Diseases and Hospital Epidemiology, and Department of Clinical Research, University and University Hospital of Basel

\section{Ildefonso Espigado}

Hospital Virgen del Rocío

\section{Giulia DRAGONETTI}

Hematology Unit, Fondazione Policlinico Universitario Agostino Gemelli - IRCCS

\section{Luana Fianchi}

Universita' Cattolica S. Cuore

\section{Maria llaria Del Principe}

UOC Ematologia Policlinico TorVergata

\section{Alba CABIRTA}

Department of Hematology, Vall d'Hebron Hospital Universitari, Experimental Hematology, Vall d'Hebron Institute of Oncology (VHIO), Vall d'Hebron Barcelona Hospital Campus

Irati ORMAZABAL-VÉLEZ

Complejo Hospitalario de Navarra

\section{Ozren Jaksic}

University Hospital Dubrava

\section{Caterina BUQUICCHIO}

Ematologia con Trapianto, Ospedale Dimiccoli Barletta 


\section{Valentina BONUOMO}

Department of Medicine, Section of Hematology, University of Verona

\section{Josip Batinić}

University Hospital Center Zagreb and University of Zagreb School of Medicine

\section{Ali S. OMRANI}

Hamad Medical Corporation, Division of Infectious Diseases

\section{Sylvain Lamure}

CHU de Montpellier, UMR-CNRS 5535, Université de Montpellier https://orcid.org/0000-0001-5980-305X

\section{Olimpia Finizio}

Cardarelli General Hospital

\section{Noemí FERNÁNDEZ}

Hospital Universitario Marqués de Valdecilla

\section{Iker FALCES-ROMERO}

La Paz University Hospital

\section{Ola BLENNOW}

Department of Infectious Diseases, Karolinska University Hospital

\section{Rui BERGANTIM}

Centro Hospitalar e Universitário São João

\section{Natasha Ali}

Aga Khan University

\section{Sein WIN}

Department of Clinical Haematology, Yangon General Hospital, University of Medicine

\section{Jens VAN PRAET}

Department of Nephrology and Infectious diseases, AZ Sint-Jan Brugge-Oostende AV

\section{Maria Chiara Tisi}

San Bortolo Hospital

\section{Ayten SHIRINOVA}

Azerbaijan Scientific Research Hematology and Transfusilogy Institute

\section{Martin SCHÖNLEIN}

Department of Oncology, Hematology and Bone Marrow Transplantation with Section of Pneumology, University Medical Center Hamburg-Eppendorf

\section{Juergen PRATTES}

Medical University of Graz, Department for Infectious Diseases

\section{Monica PIEDIMONTE}

AOU Sant'Andrea

\section{Verena Petzer}

Medical University of Innsbruck

\section{Milan NAVRÁTIL}

Head of the ICU and Transplant Unit, Department of Hematooncology, University Hospital of Ostrava

\section{Austin Kulasekararaj}

Kings College https://orcid.org/0000-0003-3180-3570

\section{Pavel Jindra}

University Hospital, Pilsen https://orcid.org/0000-0002-8415-7069

\section{Jiří SRAMEK}

University Hospital Pilsen

\section{Andreas Glenthøj}


Department of Hematology, Rigshospitalet, Copenhagen University Hospital

\section{Rita FAZZI}

AOUP - Azienda Ospedaliera Università Pisana - Cisanello

Cristina de Ramón

Hematology Department, University Hospital of Salamanca, Institute of Biomedical Research of Salamanca (IBSAL)

Chiara Cattaneo

ASST Spedali Civili di Brescia https://orcid.org/0000-0003-0031-3237

\section{Maria CALBACHO}

Hospital Universitario 12 de Octubre

\section{Nathan C. BAHR}

University of Kansas Medical Center

\section{Shaimaa Saber EL-ASHWL}

Oncology Center, Mansoura University

\section{Raúl Córdoba}

Lymphoma Unit, Deparment of Hematology, Fundacion Jimenez Diaz University Hospital, Health Research Institute IIS-FJD

\section{Michaela HANAKOVA}

Institute of Hematology and Blood Transfusion

\section{Giovanni ZAMBROTTA}

Azienda Ospedaliera San Gerardo - Monza

\section{Mariarita Sciumè}

Hematology Unit, Fondazione IRCCS Ca' Granda Ospedale Maggiore Policlinico

\section{Stephen Booth}

Department of Oncology, University of Oxford,

\section{Raquel NUNES-RODRIGUES}

Portuguese Institute of Oncology

\section{Maria Vittoria SACCHI}

Azienda Ospedaliera Nazionale SS. Antonio e Biagio e Cesare Arrigo

\section{Nicole GARCÍA-POUTÓN}

Department of Infectious Diseases, Hospital Clinic de Barcelona, University of Barcelona, IDIBAPS

\section{Juan-Alberto MARTÍN-GONZÁLEZ}

Hospital Univesitario Virgen del Rocío

\section{Sofya KHOSTELIDI}

North-Western State Medical University named after Iliá Ilich Méchnikov

\section{Stefanie GRÄFE}

Universitätsklinikum Hamburg Eppendorf

\section{Laman RAHIMLI}

University of Cologne, Faculty of Medicine and University Hospital Cologne, Department I of Internal Medicine, Excellence Center for Medical Mycology (ECMM)

alessandro busca

AOU Citta' della Salute e della Scienza

\section{Paolo Corradini}

Department of Oncology and Hemato-Oncology, University of Milan, Milan https://orcid.org/0000-0002-9186-1353

\section{Martin HOENIGL}

Division of Infectious Diseases, Department of Internal Medicine, Medical University of Graz

\section{Nikolai KLIMKO}

North-Western State Medical University named after Iliá Ilich Méchnikov 


\section{Philipp Koehler}

University of Cologne, Faculty of Medicine and University Hospital Cologne, Department I of In-ternal Medicine, Center for Integrated Oncology Aachen Bonn Cologne Duesseldorf (CIO ABCD), Excellence

\section{Antonio PAGLIUCA}

Department of Hematological Medicine, Kings College Hospital NHS Foundation Trust

\section{Francesco Passamonti}

University of Insubria https://orcid.org/0000-0001-8068-5289

\section{Oliver Cornely}

University Hospital of Cologne, Internal Medicine https://orcid.org/0000-0001-9599-3137

\section{Livio pagano}

Università https://orcid.org/0000-0001-8287-928X

\section{Article}

Keywords: COVID-19, pandemic, acute myeloid leukemia, European Hematology Association, AML treatment, treatment delay, treatment suspension

Posted Date: February 4th, 2022

DOI: https://doi.org/10.21203/rs.3.rs-1323457/v1

License: @ (i) This work is licensed under a Creative Commons Attribution 4.0 International License. Read Full License 


\section{Abstract}

Patients with acute myeloid leukemia (AML) are at high risk of mortality from coronavirus disease 2019 (COVID-19). The optimal management of AML patients with COVID-19 has not been established. Our multicenter study included 388 adult AML patients with COVID-19 diagnosis between February 2020 and October 2021. The vast majority were receiving or had received AML treatment in the prior 3 months. COVID-19 was severe in $41.2 \%$ and critical in $21.1 \%$ of cases. The chemotherapeutic schedule was modified in 174 patients (44.8\%), delayed in 68 and permanently discontinued in 106. After a median follow-up of 325 days, 180 patients (46.4\%) had died. Death was attributed to COVID-19 (43.3\%), AML (26.1\%) or to a combination of both (26.7\%). Active disease, older age, and treatment discontinuation were associated with death, whereas AML treatment delay was protective. Seventy-nine patients had a simultaneous AML and COVID-19 diagnosis, with an improved survival when AML treatment could be delayed. Patients with COVID-19 diagnosis between January and August 2020 had a significantly lower survival. COVID-19 in AML patients was associated with a high mortality rate and modifications of therapeutic algorithms. The best approach to improve survival was to delay AML treatment.

\section{Introduction}

Acute myeloid leukemia (AML) is an aggressive malignancy often requiring immediate chemotherapeutic treatment due to high risk of early disease-related life-threatening complications including death [1]. AML patients are severely immunocompromised, and infections are frequently associated with both, the disease-related weakened immunity and the aggressive chemotherapeutic regimen [2]. Despite a lower relevance as compared to bacterial and fungal infections, respiratory viruses may also affect AML patients, particularly during seasonal epidemics [3].

Coronavirus disease 2019 (COVID-19), caused by severe acute respiratory syndrome coronavirus 2 (SARS-CoV-2), is associated with a severe clinical presentation in AML patients. Most of the studies performed in the pre-vaccine era reported mortality rates higher than 40\% [4-8]. The literature regarding COVID-19 in AML patients is limited to small cohorts [9-10], case reports and case series [10-14], expert opinions and consensus, $[13,15]$ or series reporting both patients with AML and acute lymphoblastic leukemia [16-17]. Therefore, specific data on large patient cohorts with long-term follow-up are still lacking. To the best of our knowledge, there are still no evidence-based algorithms guiding clinicians to choose the best therapeutic approach and timing, particularly in patients with a simultaneous diagnosis of AML and COVID-19 diagnosis.

Thus, in order to establish the best therapeutic approach, we aimed to describe clinical features and long-term follow-up of a large cohort of AML patients with COVID-19 registered in the EPICOVIDEHA registry, with a particular focus on patients with a concomitant diagnosis of AML and COVID-19.

\section{Material And Methods}

\section{Study design, patients, and procedures}

This is an observational multicenter study of patients with AML who developed COVID-19 between February 2020 and October 2021. Our analysis comprised data from the EPICOVIDEHA (www.clinicaltrials.gov; ID NCT04733729) international open web-based registry for patients with hematological malignancies (HM) and SARS-CoV-2 infections initiated in February 2020 by members of the Scientific Working Group (SWG) Infection in Hematology of the European Hematology Association (EHA). EPICOVIDEHA was approved by the local ethics committee of the Fondazione Policlinico Universitario Agostino Gemelli - IRCCS, Università Cattolica del Sacro Cuore of Rome, Italy (ID 3226). Additionally, the respective local ethics committee of each participating institution approved as appropriate. EPICOVIDEHA methodology has been described elsewhere [18]. The electronic case report form (eCRF) is accessible online via www.clinicalsurveys.net (EFS Summer 2021, TIVIAN GmbH, Cologne, Germany) [19]. Each documented patient was reviewed and validated by experts in infectious 
diseases and hematology. Inclusion criteria were: a) active AML within the last five years before COVID-19 diagnosis, b) adult patients $\geq 18$ years old, and c) laboratory-based diagnosis of SARS-CoV-2 infection. Data on patient baseline conditions pre-COVID-19 (i.e., age, sex, AML status at COVID-19 diagnosis, comorbidities), AML clinical management (i.e., last chemotherapy strategy, hematopoietic stem-cell transplantation [HSCT], COVID-19 diagnosis and management (i.e., the reason for a diagnostic test, symptoms at onset, hospitalization) and outcome (i.e., mortality, attributable mortality [assessed by the medical team in charge of the patient], last day of follow-up) were also recorded. Additionally, information regarding AML treatment modifications (i.e., delay or discontinuation) due to COVID-19, and the contribution of the diagnosis of COVID-19 in AML relapse or AML status at last day of follow up was also collected. Status of hematological malignancy at COVID-19 onset and last follow up was defined as active (onset, stable disease, refractory/resistant) or controlled (complete response) based on the reports from the respective participating institution. COVID-19 severity was graded according to international standards as previously described [4, 20-21]. Patients were divided in three time periods as follows: a) January 2020 to August 2020, to cover the first global wave of the pandemic; b) September 2020 to February 2021, with the patients diagnosed in the final holiday period of 2020-2021; and c) March 2021 to September 2021, including patients diagnosed after the vaccines became available.

\section{Study objectives}

The primary objective of this study was to evaluate the epidemiology and the outcome of AML patients with COVID- 19 . Secondary objectives were: 1) to estimate the prevalence of disease severity (i.e., asymptomatic, mild, severe disease and ICU admission; 2) to describe the overall case-fatality rate; and 3) to stratify patients according to their treatment phase (induction, consolidation, maintenance, palliative, reinduction), chemotherapeutic program modification due to COVID-19 (treatment discontinuation, delay or continuation), and timing of COVID-19 diagnosis.

\section{Sample size and statistical analysis}

No a priori sample size calculation was performed for this analysis. Categorical variables were described using frequencies and percentages, whereas continuous variables were expressed as median, interquartile range (IQR) and absolute range. A Cox regression hazard model was designed and run with variables considered to play a role in the mortality of AML patients with COVID-19, as previously described [4]. A multivariable Cox regression model was calculated with the Wald backward method, and only those variables with $\mathrm{p} \leq 0.1$ were displayed. Mortality was analyzed using Kaplan-Meier survival plots. Log-rank test was used to compare the survival probability of the patients included in the different models. A p-value $\leq 0.05$ was found statistically significant. SPSS v27.0 was employed for statistical analyses (SPSS, IBM Corp., Chicago, IL, United States).

\section{Role of funding source}

EPICOVIDEHA has received funds from Optics COMMIT TM (COVID-19 Unmet Medical Needs and Associated Research Extension) COVID-19 RFP program by GILEAD Science, United States (Project 2020-8223). The funder of the study had no role in study design, data analysis, interpretation, or writing of the report. All authors had full access to the data and had final responsibility for the decision to submit for publication.

\section{Results}

Between February 2020 and October 2021, 556 consecutive adult AML patients with confirmed SARS-CoV-2 infection were reported in the EPICOVIDEHA registry, from 132 centres and 20 countries around the world. Out of these patients, 168 (30.2\%) were excluded from this analysis due to missing data.

The demographic and clinical characteristics of the remaining 388 patients are shown in Table 1. The median age was 59 years (IQR: 45-70) with a slight male predominance (52.6\%). Most patients had at least one underlying comorbidity with chronic cardiopathy (i.e., hypertension, obstructive arteriopathy, atrial fibrillation) being the most frequent, whereas 175 
patients (45.1\%) had comorbidities. At the time of COVID-19 diagnosis, 196 patients (50.5\%) had controlled AML, and 192 (49.5\%) had active disease, including 79 (20.4\%) patients at AML onset. Only 110 patients (28.3\%) were not on active treatment. Overall, 237 patients (64.6\%) had received intensive chemotherapy and transplantation, being the most common strategies immediately before COVID-19. The chemotherapeutic program was modified because of COVID-19 in 174 (44.8\%) patients; in 106 (60.9\%) it was permanently discontinued, whereas in the remaining $68(39.1 \%)$ it was delayed and resumed after a median of 1 month (IQR: 1-2) since COVID-19 diagnosis. At COVID-19 onset, 71 (18.3\%) and 53 (13.7\%) patients had neutrophil and lymphocyte counts below $0.5 \times 10^{9} / \mathrm{mm}^{3}$ and $0.2 \times 10^{9} / \mathrm{mm}^{3}$, respectively. Two hundred and twenty patients (56.7\%) had pulmonary symptoms at COVID-19 onset, mainly cough and dyspnoea, 82 (21.1\%) exhibited only extra-pulmonary symptoms and 86 (22.2\%) were asymptomatic and diagnosed with COVID-19 after screening. As shown in Table 1, COVID-19 severity was critical in 82 patients (21.1\%), severe in 160 (41.2\%), mild in 69 (17.8\%), and asymptomatic in the remaining cases (19.6\%). Overall, 293 patients (75.5\%) were hospitalized during the COVID-19 for a median of 17 days (IQR: 8-30). Eighty-two patients (21.1\%) were admitted to an intensive care unit (ICU) for a median stay of 10 days (IQR: 5-20), 63 (76.8\%) of whom required invasive mechanical ventilation. 
Demographic and clinical features of 388 AML patients at COVID-19 diagnosis.

\begin{tabular}{|c|c|c|}
\hline & $\mathbf{n}$ & $\%$ \\
\hline \multicolumn{3}{|l|}{ Sex } \\
\hline Female & 184 & 47.4 \\
\hline Male & 204 & 52.6 \\
\hline Age, median (IQR) [range] & \multicolumn{2}{|c|}{$59(45-70)$ [18-89] } \\
\hline Comorbidities & 213 & 54.9 \\
\hline \multicolumn{3}{|c|}{ Status AML at COVID-19 diagnosis } \\
\hline Controlled disease & 196 & 50.5 \\
\hline Complete remission & 196 & 50.5 \\
\hline Active disease & 192 & 49.5 \\
\hline Onset & 79 & 20.4 \\
\hline Stable disease & 48 & 12.4 \\
\hline Refractory/Resistant & 65 & 16.8 \\
\hline \multicolumn{3}{|c|}{ Last/ongoing treatment strategy before COVID-19 } \\
\hline Treatment & 367 & 94.6 \\
\hline Conventional chemotherapy & 250 & 64.4 \\
\hline Last month & 172 & 44.3 \\
\hline Last three months & 46 & 11.9 \\
\hline$>3$ months & 32 & 8.2 \\
\hline HSCT & 72 & 18.6 \\
\hline Last month & 8 & 2.1 \\
\hline Last three months & 11 & 2.8 \\
\hline$>3$ months & 53 & 13.7 \\
\hline Supportive measures & 45 & 11.6 \\
\hline Last month & 27 & 7.0 \\
\hline Last three months & 9 & 2.3 \\
\hline$>3$ months & 4 & 1.0 \\
\hline Not stated & 5 & 1.3 \\
\hline No treatment & 21 & 5.4 \\
\hline COVID-19 infection & & \\
\hline
\end{tabular}

AML, acute myeloid leukaemia; BAL, bronchioalveolar lavage; COVID-19, coronavirus disease 2019; HSCT, hematopoietic stem cell transplantation; ICU, intensive care unit; IQR, interquartile range; $\mathbf{m m}^{\mathbf{3}}$, cubit meters

'Data can be super additive 


\begin{tabular}{|c|c|c|}
\hline & $\mathbf{n}$ & $\%$ \\
\hline Critical infection & 82 & 21.1 \\
\hline Severe infection & 160 & 41.2 \\
\hline Mild infection & 69 & 17.8 \\
\hline Asymptomatic & 77 & 19.8 \\
\hline \multicolumn{3}{|l|}{ COVID-19 diagnosis } \\
\hline Swab & 376 & 96.9 \\
\hline $\mathrm{BAL}+\mathrm{Swab}$ & 5 & 1.3 \\
\hline Serology & 4 & 1.0 \\
\hline BAL & 3 & 0.8 \\
\hline \multicolumn{3}{|l|}{ Symptoms at COVID-19 onset } \\
\hline Pulmonary & 144 & 37.1 \\
\hline Screening & 86 & 22.2 \\
\hline Extrapulmonary & 82 & 21.1 \\
\hline Pulmonary + Extrapulmonary & 76 & 19.6 \\
\hline \multicolumn{3}{|l|}{ Neutrophils $\left(\times 10^{6} / \mathrm{mm}^{3}\right)^{\circ}$} \\
\hline$\leq 0.5$ & 71 & 18.3 \\
\hline $0.501-0.999$ & 38 & 9.8 \\
\hline$\geq 1$ & 203 & 52.3 \\
\hline \multicolumn{3}{|l|}{ Lymphocytes $\left(\times 10^{6} / \mathrm{mm}^{3}\right)^{\circ}$} \\
\hline$\leq 0.2$ & 53 & 13.7 \\
\hline $0.201-0.499$ & 56 & 14.4 \\
\hline$\geq 0.5$ & 211 & 54.4 \\
\hline \multicolumn{3}{|l|}{ Stay during COVID-19 } \\
\hline Admitted in hospital & 293 & 75.5 \\
\hline Duration of the stay in hospital, median days (IQR) [range] & \multicolumn{2}{|c|}{$17(8-30)$ [1-210] } \\
\hline ICU stay & 82 & 21.1 \\
\hline Duration of the ICU stay, median days (IQR) [range] & \multicolumn{2}{|c|}{$10(5-20)[1-111]$} \\
\hline Invasive mechanical ventilation & 63 & 16.2 \\
\hline Non-invasive mechanical ventilation & 19 & 4.9 \\
\hline At home & 117 & 30.2 \\
\hline \multicolumn{3}{|c|}{$\begin{array}{l}\text { AML, acute myeloid leukaemia; BAL, bronchioalveolar lavage; COVID-19, coronavirus disease 2019; HSCT, } \\
\text { hematopoietic stem cell transplantation; ICU, intensive care unit; IQR, interquartile range; } \text { mm³ }^{3} \text {, cubit meters }\end{array}$} \\
\hline
\end{tabular}




\begin{tabular}{|c|c|c|}
\hline & $\mathbf{n}$ & $\%$ \\
\hline \multicolumn{3}{|l|}{ Outcome } \\
\hline Alive & 208 & 53.6 \\
\hline Observation time, median days (IQR) [range] & \multicolumn{2}{|c|}{$325(117-386)[3-639$} \\
\hline Dead & 180 & 46.4 \\
\hline Observation time, median days (IQR) [range] & \multicolumn{2}{|c|}{$20(8-58)[0-528]$} \\
\hline \multicolumn{3}{|l|}{ Reason for death ${ }^{\circ}$} \\
\hline COVID-19 & 78 & 43.3 \\
\hline COVID-19 + Haematological malignancy & 48 & 26.7 \\
\hline Haematological malignancy & 47 & 26.1 \\
\hline Unknown reasons & 7 & 3.9 \\
\hline \multicolumn{3}{|c|}{$\begin{array}{l}\text { AML, acute myeloid leukaemia; BAL, bronchioalveolar lavage; COVID-19, coronavirus disease 2019; HSCT, } \\
\text { hematopoietic stem cell transplantation; ICU, intensive care unit; IQR, interquartile range; } \mathrm{mm}^{3} \text {, cubit meters }\end{array}$} \\
\hline \multicolumn{3}{|l|}{${ }^{\circ}$ Data can be super additive } \\
\hline
\end{tabular}

Patients were followed-up for a median of 104 days (IQR: 18-346) since COVID-19 diagnosis; 325 days (IQR: 117-386) in 208 (53.6\%) surviving patients versus 20 days (IQR: 8-58) in the 180 (46.4\%) patients who died. The reported primary reason for death was COVID-19 in 78 (43.3\%) patients, AML in $47(26.1 \%)$, a combination of both in $48(26.7 \%)$ and unknown in 7 patients (3.9\%), as shown in Table 1 and Figure 1 . The mortality rate of patients with an ongoing or recent $(<1$ month before COVID-19 diagnosis) AML treatment, so as those treated until 1 to 3 months before COVID-19 diagnosis was significantly higher than those receiving a treatment until 3 months or earlier before COVID-19 $(p<0.001)$, as shown in Figure 2. When considering AML patients with the last chemotherapy < 1 month before COVID-19 diagnosis, a higher mortality rate was observed in 68 (80.9\%) patients who discontinued treatment, regardless of the treatment phase (Figure 3). Furthermore, a significantly lower mortality rate was observed in 49 (18.4\%) patients with chemotherapy delay (overall mortality rate: $18.4 \%, n=49)$, as opposed to those patients with no delay $(37.5 \%, n=9)(p<0.001)$, regardless of the treatment phase (Figure 2 and Figure 4$)$. The overall mortality rate of patients in induction $(67.1 \%, n=51)$ or reinduction $(77.7 \%, n=28)$ was higher as compared to those in consolidation $(20 \%, n=10)$ during the last month prior to COVID-19 $(p<0.001)$. In the univariable analysis, several factors were associated with an increased mortality (Table 2): older age, previous comorbidities (i.e., chronic cardiopathy or renal impairment), active malignancy, critical COVID-19, or permanent AML treatment discontinuation. On the contrary, having a neutrophil or lymphocyte count above $0.5 \times 10^{9} / \mathrm{mm}^{3}$ and $0.2 \times 10^{9} / \mathrm{mm}^{3}$, respectively, AML treatment $>3$ months before COVID-19 diagnosis and AML treatment delay were associated to a reduced mortality. In the multivariable model, active disease (HR: 4.197, $p<0.001$ ), older age (HR: 1.016, $p=0.012$ ), and treatment discontinuation (HR: 4.417, p<0.001) were associated with a higher mortality, as opposed to treatment delay, which was found to be protective (HR: $0.367, p=0.027$ ). After a time-dependent analysis, it was observed that overall survival in patients with COVID-19 diagnosis between January 2020 and August 2020 was significantly lower survival than those who were diagnosed between September 2020 and February 2021 and between March 2021 and September 2021 ( $p=0.037$; Figure S2). 
Table 2

Overall mortality predictors of death in AML patients with COVID-19.

\begin{tabular}{|c|c|c|c|c|c|c|c|c|}
\hline \multirow[t]{2}{*}{ OVERALL MORTALITY } & \multicolumn{4}{|c|}{ Univariable } & \multicolumn{4}{|c|}{ Multivariable } \\
\hline & $p$ & HR & $95 \% \mathrm{Cl}$ & & $p$ & HR & $95 \% \mathrm{Cl}$ & \\
\hline Lower & valuer & Lower & Upper & & value & & & \\
\hline limit & limit & limit & limit & & & & & \\
\hline \multicolumn{9}{|l|}{ Sex } \\
\hline Female & - & - & - & - & - & - & - & - \\
\hline Male & 0.403 & 1.135 & 0.844 & 1.526 & - & - & - & - \\
\hline Age & $<0.001$ & 1.029 & 1.019 & 1.040 & 0.012 & 1.016 & 1.004 & 1.028 \\
\hline Comorbidities & 0.001 & 1.699 & 1.251 & 2.308 & 0.437 & 0.831 & 0.520 & 1.326 \\
\hline \multicolumn{9}{|l|}{ Malignancy status } \\
\hline Controlled disease & - & - & - & - & - & - & - & - \\
\hline Active disease & $<0.001$ & 4.353 & 3.111 & 6.092 & $<0.001$ & 4.197 & 2.196 & 8.020 \\
\hline \multicolumn{9}{|l|}{ COVID-19 infection } \\
\hline Asymptomatic & - & - & - & - & - & - & - & - \\
\hline Mild infection & 0.370 & 0.770 & 0.435 & 1.363 & 0.566 & 0.804 & 0.382 & 1.694 \\
\hline Severe infection & 0.454 & 1.187 & 0.758 & 1.857 & 0.812 & 1.073 & 0.600 & 1.920 \\
\hline Critical infection & $<0.001$ & 3.624 & 2.306 & 5.696 & 0.249 & 1.417 & 0.783 & 2.565 \\
\hline \multicolumn{9}{|l|}{ Neutrophils $\left(\times 10^{6} / \mathrm{mm}^{3}\right)$} \\
\hline$\leq 0.5$ & - & - & - & - & - & - & - & - \\
\hline $0.501-0.999$ & 0.017 & 0.529 & 0.314 & 0.891 & 0.359 & 0.761 & 0.424 & 1.365 \\
\hline$\geq 1$ & $<0.001$ & 0.426 & 0.299 & 0.608 & 0.473 & 1.198 & 0.732 & 1.961 \\
\hline \multicolumn{9}{|l|}{ Lymphocytes $\left(\times 10^{6} / \mathrm{mm}^{3}\right)$} \\
\hline$\leq 0.2$ & - & - & - & - & - & - & - & - \\
\hline $0.201-0.499$ & 0.982 & 1.006 & 0.624 & 1.620 & 0.309 & 0.702 & 0.355 & 1.389 \\
\hline$\geq 0.5$ & 0.009 & 0.581 & 0.388 & 0.872 & 0.144 & 0.661 & 0.379 & 1.152 \\
\hline \multicolumn{9}{|l|}{ Last chemotherapy/HSCT } \\
\hline In the last month & - & - & - & - & - & - & - & - \\
\hline In the last 3 months & 0.464 & 0.863 & 0.583 & 1.279 & 0.903 & 1.038 & 0.568 & 1.897 \\
\hline $\begin{array}{l}\text { Chemotherapy ended }>3 \text { months before } \\
\text { COVID-19 }\end{array}$ & $<0.001$ & 0.368 & 0.235 & 0.577 & 0.225 & 2.204 & 0.614 & 7.909 \\
\hline Not stated & 0.291 & 0.346 & 0.048 & 2.479 & 0.566 & 1.916 & 0.208 & 17.667 \\
\hline
\end{tabular}

AML, acute myeloid leukemia; COVID-19, coronavirus disease 2019; ICU, intensive care unit; HSCT, hematopoietic stem cell transplantation; $\mathrm{mm}^{3}$, cubic meters; TX, therapeutic program for AML. 


\begin{tabular}{|c|c|c|c|c|c|c|c|c|}
\hline \multirow{3}{*}{$\begin{array}{l}\text { OVERALL MORTALITY } \\
\text { Not applicable }\end{array}$} & \multicolumn{4}{|c|}{ Univariable } & \multicolumn{4}{|c|}{ Multivariable } \\
\hline & \multirow{2}{*}{$\begin{array}{l}p \\
\text { yalye }\end{array}$} & \multirow{2}{*}{$\begin{array}{l}\text { HR } \\
1.018\end{array}$} & \multicolumn{2}{|l|}{$95 \% \mathrm{Cl}$} & \multirow{2}{*}{$\begin{array}{l}\text { p } \\
\text { yadift }\end{array}$} & \multirow{2}{*}{$\begin{array}{l}\text { HR } \\
0.891\end{array}$} & \multicolumn{2}{|l|}{$95 \% \mathrm{Cl}$} \\
\hline & & & 0.548 & 1.892 & & & 0.333 & 2.386 \\
\hline \multicolumn{9}{|l|}{ AML treatment delay } \\
\hline TX NOT delayed and NOT discontinued & - & - & - & - & - & - & - & - \\
\hline TX delayed but NOT discontinued & 0.013 & 0.361 & 0.161 & 0.808 & 0.027 & 0.367 & 0.151 & 0.891 \\
\hline TX discontinued & $<0.001$ & 4.271 & 2.372 & 7.690 & $<0.001$ & 4.417 & 2.306 & 8.460 \\
\hline \multicolumn{9}{|l|}{ Relapse after COVID-19 } \\
\hline No & - & - & - & - & - & - & - & - \\
\hline Yes, due to COVID-19 & 0.350 & 0.712 & 0.350 & 1.451 & - & - & - & - \\
\hline Yes, NOT due to COVID-19 & 0.796 & 0.928 & 0.527 & 1.636 & - & - & - & - \\
\hline Unknown & 0.182 & 1.746 & 0.770 & 3.958 & - & - & - & - \\
\hline
\end{tabular}

Table 3 describes the demographic and clinical features of the 79 patients with a simultaneous AML and COVID-19 diagnosis. In 18 patients (22.8\%), COVID-19 was diagnosed before induction start, resulting in a treatment delay. A higher overall survival was observed in patients with treatment delay (Table 3, Figure S1). 
Table 3

Demographic and clinical features of 79 AML patients at malignancy onset at COVID-19 diagnosis.

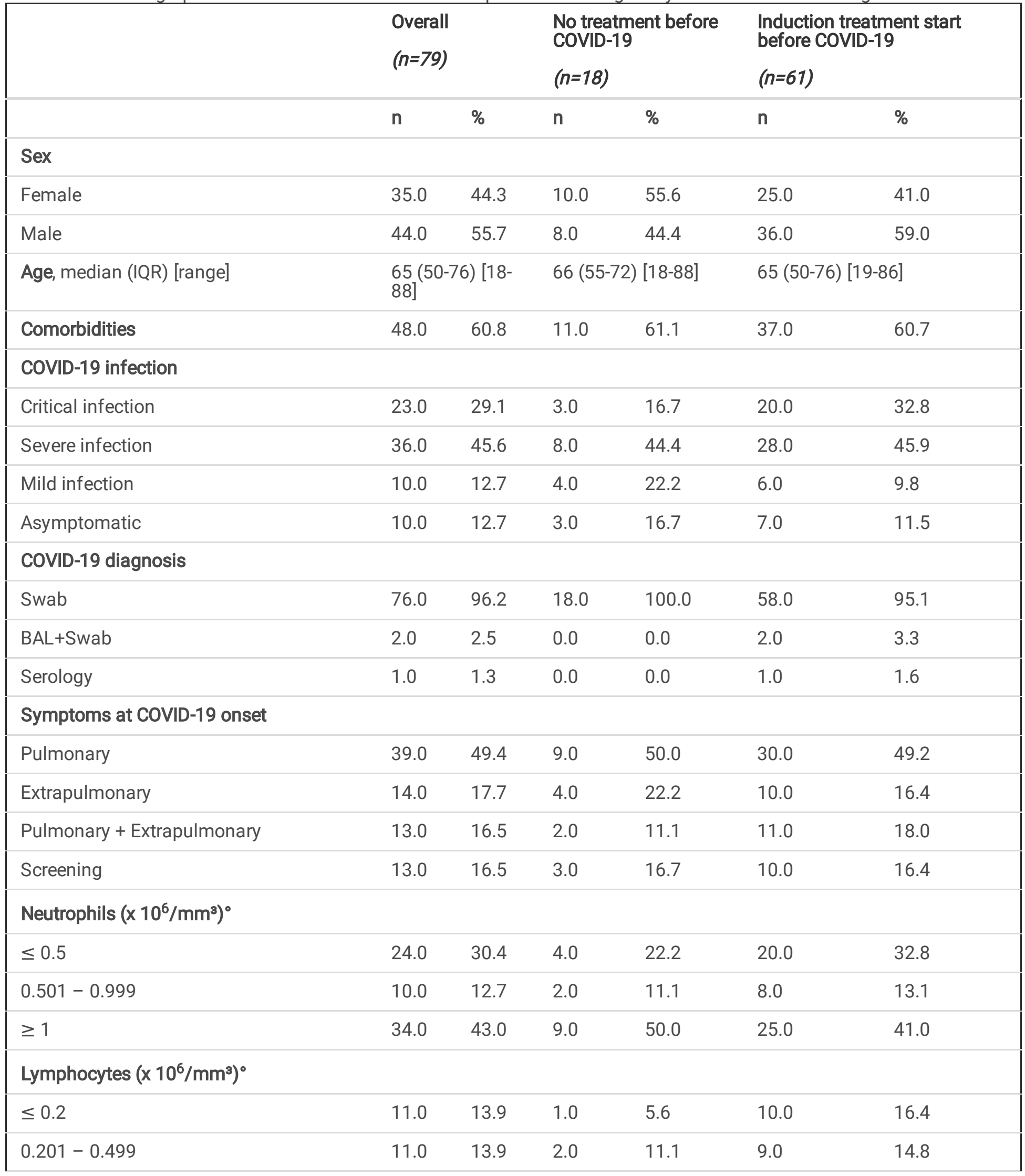

AML, acute myeloid leukemia; BAL, bronchioalveolar lavage; COVID-19, coronavirus disease 2019; HSCT, hematopoietic stem cell transplantation; ICU, intensive care unit; IQR, interquartile range; $\mathbf{~ m m}^{3}$, cubit meters

${ }^{\circ}$ Data can be super additive 


\begin{tabular}{|c|c|c|c|c|c|c|}
\hline \multirow[b]{2}{*}{$\geq 0.5$} & \multicolumn{2}{|c|}{$\begin{array}{l}\text { Overall } \\
(n=79)\end{array}$} & \multicolumn{2}{|c|}{$\begin{array}{l}\text { No treatment before } \\
\text { COVID-19 } \\
(n=18)\end{array}$} & \multicolumn{2}{|c|}{$\begin{array}{l}\text { Induction treatment start } \\
\text { before COVID-19 } \\
(n=61)\end{array}$} \\
\hline & 50 & 63.3 & 13.0 & 72.2 & 37.0 & 60.7 \\
\hline \multicolumn{7}{|l|}{ Stay during COVID-19 } \\
\hline Admitted in hospital & 73 & 92.4 & 15.0 & 83.3 & 58.0 & 95.1 \\
\hline $\begin{array}{l}\text { Duration of the stay in hospital, median } \\
\text { days (IQR) [range] }\end{array}$ & \multicolumn{2}{|c|}{$\begin{array}{l}20(9-32)[2- \\
106]\end{array}$} & \multicolumn{2}{|c|}{$14(4-24)[2-86]$} & \multicolumn{2}{|c|}{$22(9-36)[3-106]$} \\
\hline ICU stay & 23 & 29.1 & 3.0 & 16.7 & 20.0 & 32.8 \\
\hline $\begin{array}{l}\text { Duration of the ICU stay, median days } \\
\text { (IQR) [range] }\end{array}$ & \multicolumn{2}{|c|}{7 (4-12) [1-32] } & \multicolumn{2}{|c|}{$5(2-10)[2-10]$} & \multicolumn{2}{|c|}{$7(4-12)[1-32]$} \\
\hline Invasive mechanical ventilation & 18 & 22.8 & 1.0 & 5.6 & 17.0 & 27.9 \\
\hline Non-invasive mechanical ventilation & 4 & 5.1 & 0.0 & 0.0 & 4.0 & 6.6 \\
\hline At home & 10 & 12.7 & 4.0 & 22.2 & 6.0 & 9.8 \\
\hline \multicolumn{7}{|l|}{ Outcome } \\
\hline Alive & 26 & 32.9 & 8.0 & 44.4 & 18.0 & 29.5 \\
\hline $\begin{array}{l}\text { Observation time, median days (IQR) } \\
\text { [range] }\end{array}$ & \multicolumn{2}{|c|}{$\begin{array}{l}266.5(85-386) \\
{[11-613]}\end{array}$} & \multicolumn{2}{|c|}{$\begin{array}{l}266.5(122-353)[44- \\
613]\end{array}$} & \multicolumn{2}{|c|}{$277.5(75-408)[11-601]$} \\
\hline Dead & 53 & 67.1 & 10.0 & 55.6 & 43.0 & 70.5 \\
\hline $\begin{array}{l}\text { Observation time, median days (IQR) } \\
\text { [range] }\end{array}$ & $\begin{array}{l}19( \\
528\end{array}$ & 5) $[0-$ & $14(5$ & [0-528] & $21(7-$ & \\
\hline \multicolumn{7}{|l|}{ Reason for death $^{\circ}$} \\
\hline COVID-19 & 20 & 37.7 & 3 & 30.0 & 17 & 39.5 \\
\hline COVID-19 + Hematological malignancy & 16 & 30.2 & 4 & 40.0 & 12 & 27.9 \\
\hline Hematological malignancy & 17 & 32.1 & 3 & 30.0 & 14 & 32.6 \\
\hline \multicolumn{7}{|c|}{$\begin{array}{l}\text { AML, acute myeloid leukemia; BAL, bronchioalveolar lavage; COVID-19, coronavirus disease 2019; HSCT, hematopoieti } \\
\text { stem cell transplantation; ICU, intensive care unit; IQR, interquartile range; mm³, cubit meters }\end{array}$} \\
\hline
\end{tabular}

\section{Discussion}

Currently, there is a gap of knowledge regarding COVID-19 in AML patients, as the current evidence is restricted to small patient cohorts, case reports/series, or expert opinions [9-17]. This gap has resulted in a difficulty to establish the best strategy to manage AML patients during the pandemic [22-23]. Altogether, the current evidence suggests that AML patients often present with a severe clinical form, with frequent respiratory distress and very high mortality rate, between 40 and $50 \%$ as compared to the pre-vaccine era. Here we present, to the best of our knowledge, the largest survey on AML patients with COVID-19, with 388 patients reported from 132 institutions, with a special focus on the long-term follow-up. The data presented in our manuscript confirm that AML patients frequently have a severe clinical presentation (41.2\%) of COVID-19, mainly with respiratory symptoms, and a high rate of ICU admission (21.1\%). 
Neutrophil and lymphocyte counts were not found to be significantly associated with mortality in our multivariable model. The potential role of neutropenia as a risk factor for death in AML is of particular relevance considering that neutrophil function impairment is a typical feature of this malignancy. There are many studies addressing neutropenia as a potential risk factor in COVID-19, but only four of them were able to support its role as a factor affecting survival [24-27]. In particular, a recent study from the Memorial Sloan Kettering Cancer Center (New York, NY, USA), showed that neutropenia between the seven days immediately prior to and up to 28 days after SARS-CoV-2 diagnosis, was associated with increased odds of death [27]. In our study, severe neutropenia was found to be significantly associated with the risk of death at univariable analysis, however, this association was lost in the multivariable model, suggesting that severe neutropenia may not be associated with death in AML patients developing COVID-19.

In our study, we tried to establish the best therapeutic strategy for AML patients with COVID-19. So far, the best therapeutic option for these patients and timing for treatment initiation was only based on expert opinions and consensus [22-23], given the lack of evidence-based algorithms to guide clinicians. This is particularly relevant for naïve AML patients with a concomitant symptomatic SARS-CoV-2 infection. The general recommendation for these patients has been to postpone all treatments not requiring urgent initiation, including a limitation of cytoreductive therapies if needed [22]. Although the current dogma of considering AML a medical urgency is changing, as suggested by some recent studies [28], prompt treatment start is often recommended in routine practice, especially in patients with de novo or with relapsed/refractory disease. Our data suggest that delayed treatment is the best therapeutic option for AML patients with COVID-19, as shown by a lower death rate when treatment was postponed. Similar data were also shown by a Spanish group [9]: in their patient cohort of 108 patients, a lower mortality rate was observed in patients with delayed chemotherapy as compared with those with or without treatment modification. However, those results were observed only in the univariable analysis. Our multivariable model confirmed that a chemotherapeutic program delay was associated with a reduced death rate, having a significant protective role (HR: 0.367; $p=0.027$ ). Interestingly, even when focusing on patients with new onset AML and COVID-19, we found a better overall survival in those patients in which AML induction delay was possible. The negative impact of AML treatment discontinuation on the observed death rate in our multivariable analysis can be explained by the death of patients in which the program was discontinued. Contrary to other reports showing an increased mortality rate for patients treated with intensive chemotherapy $[6,14,16]$, we did not detect significant differences between treatment schedules. However, these data should be interpreted with caution, considering that these patients may have been older or less fit when the disease developed.

Our study found an overall mortality rate of $46.4 \%$, a value comparable to other publications [9-10]. We found that COVID19 was the primary or a main reason for death in most cases (70\%), although we deliberately decided to focus our study on overall mortality rather than on attributable mortality. Even though attributable mortality might seem more appropriate for evaluating the impact of an infection in HM patients, it can also be more easily influenced by the subjective judgment of the local physician, and consequently less reliable when used in a risk factor assessment. Conversely, the overall mortality rate is not influenced by subjective interpretations and, therefore, it is more reliable for our study aim, even when the potential role of other confounding factors, e.g., primarily leukemia progression, is taken into account. We observed an increased mortality rate associated with age and active malignancy, in agreement with previously published data [4, 9]. In addition, comorbidities and sex did not impact on mortality rate, contrary to other reports $[9,17]$, but still consistent with the previously published study from the EPICOVIDEHA registry [4].

Finally, we performed a time-dependent analysis, showing that the overall survival rate of patients diagnosed with COVID-19 from January to August 2020 was significantly lower compared to that of patients diagnosed more recently, confirming an improvement of the clinical outcome of AML patients throughout the different pandemic waves. These observations could be explained by a combination of factors, including improved management of the disease and detection of a larger number of asymptomatic/mild cases by screening programs. Although the current data on the SARS-CoV-2 pandemic show a progressive decrease of hospitalization and deaths in the overall population, HM patients remain a particularly high-risk population. 
Our study has some limitations. First, those intrinsically linked to the initial project design. We did not request any details regarding COVID-19 therapeutic approaches, as these were extremely heterogeneous and treatment recommendations changed quickly. Data on viral strains were only infrequently determined. In addition, only very few cases from our cohort $(n=7)$ were documented as breakthrough infections in fully vaccinated patients, which did not allow us to conclude on vaccine effectiveness. Interestingly, this aspect was partially addressed by our previous preliminary data on HM vaccinated patients, which showed a mild decrease in mortality of vaccinated AML patients [29].

In conclusion, our study shows that COVID-19 in AML patients poses a serious challenge, as it adds a layer of complication which can lead to modified therapeutic algorithms. The mortality rate in this patient group was very high, even when the significant reduction over the pandemic course was considered. According to our results, the best approach to improve the survival of AML patients with COVID-19 seems to delay AML treatment, whenever possible.

\section{Ethics and data protection}

EPICOVIDEHA has been approved by the local Institutional Review Board and Ethics Committee of the Fondazione Policlinico Universitario Agostino Gemelli - IRCCS, Università Cattolica del Sacro Cuore of Rome, Italy (Study ID: 3226). The corresponding local ethics committee of each participating institution may approve additionally the EPICOVIDEHA study when applicable. EPICOVIDEHA is registered at http://www.clinicaltrials.gov, identifier NCT 04733729.

\section{Declarations}

\section{Funding}

EPICOVIDEHA has received funds from Optics COMMIT ${ }^{T M}$ (COVID-19 Unmet Medical Needs and Associated Research Extension) COVID-19 RFP program by GILEAD Science, United States (Project 2020-8223).

\section{Acknowledgments}

The authors thank all contributors for their utmost contributions and support to the project during a pandemic situation and to Susann Blossfeld and Sebastian Rahn for her administrative and technical assistance.

\section{Author contributions}

LP served as the principal investigator. FM, JSG and LP contributed to study design, study supervision, and data interpretation and wrote the paper. $A B, P C, M H, N K, P K, A P, F P, A O C$ and $L P$ conceived the study idea. LP, JSG, and FM did the statistical plan, analysis and interpreted the data. All the authors recruited participants and collected and interpreted data. All authors contributed to manuscript writing and review of the manuscript. All authors agreed to be accountable for all aspects of the work in ensuring that questions related to the accuracy or integrity of any part of the work are appropriately investigated and resolved.

Competing interests

JSG has received speaker honoraria from Gilead Nordica, outside the submitted work.

AG has been consultant and advisory board member for Agios, bluebird bio, Bristol Myers Squibb, Novartis, Novo Nordisk, and has received research grants from Saniona and Sanofi, outside the submitted work.

IE has provided lectures or advisory board consultation to MSD, GILEAD, Janssen, Fundación Publica Andaluza Progreso y Salud, Grupo Español de trasplante hematopoyético y Terapia celular (GETH) and Fundación Madrileña de Hematología y Hemoterapia, outside the submitted work. 
JP has received research funding from MSD, personal fees from Gilead and Pfizer and is stockholder of AbbVie Inc. and NovoNordisk, outside the submitted work.

NCB has received funding from the NIH via K23 NS110470, outside the submitted work

PK reports grants or contracts from German Federal Ministry of Research and Education (BMBF) B-FAST (Bundesweites Forschungsnetz Angewandte Surveillance und Testung) and NAPKON (Nationales Pandemie Kohorten Netz, German National Pandemic Cohort Network) of the Network University Medicine (NUM) and the State of North Rhine-Westphalia; Consulting fees Ambu GmbH, Gilead Sciences, Mundipharma Resarch Limited, Noxxon N.V. and Pfizer Pharma; Honoraria for lectures from Akademie für Infektionsmedizin e.V., Ambu GmbH, Astellas Pharma, BioRad Laboratories Inc., European Confederation of Medical Mycology, Gilead Sciences, GPR Academy Ruesselsheim, medupdate GmbH, MedMedia, MSD Sharp \& Dohme GmbH, Pfizer Pharma GmbH, Scilink Comunicación Científica SC and University Hospital and LMU Munich; Participation on an Advisory Board from Ambu GmbH, Gilead Sciences, Mundipharma Resarch Limited and Pfizer Pharma; A pending patent currently reviewed at the German Patent and Trade Mark Office; Other non-financial interests from Elsevier, Wiley and Taylor \& Francis online outside the submitted work.

RC has been consultant and speaker faculty to Roche, Abbvie, Janssen, Astra Zeneca, Kite, Takeda, consultant to KyowaKirin, Incyte, Beigene, and has received a research grant from Pfizer, outside the submitted work.

SL has received miscellaneous support from Janssen, Gilead, Roche, Abbvie, Sanofi, Novartis, Actelion, Pfizer, some honorarium from Gilead and a research grant from Janssen, outside the submitted work.

OAC reports grants or contracts from Amplyx, Basilea, BMBF, Cidara, DZIF, EU-DG RTD (101037867), F2G, Gilead, Matinas, MedPace, MSD, Mundipharma, Octapharma, Pfizer, Scynexis; Consulting fees from Amplyx, Biocon, Biosys, Cidara, Da Volterra, Gilead, Matinas, MedPace, Menarini, Molecular Partners, MSG-ERC, Noxxon, Octapharma, PSI, Scynexis, Seres; Honoraria for lectures from Abbott, Al-Jazeera Pharmaceuticals, Astellas, Grupo Biotoscana/United Medical/Knight, Hikma, MedScape, MedUpdate, Merck/MSD, Mylan, Pfizer; Payment for expert testimony from Cidara; Participation on a Data Safety Monitoring Board or Advisory Board from Actelion, Allecra, Cidara, Entasis, IQVIA, Jannsen, MedPace, Paratek, PSI, Shionogi; A patent at the German Patent and Trade Mark Office (DE 102021113 007.7); Other interests from DGHO, DGI, ECMM, ISHAM, MSG-ERC, Wiley.

The remaining authors have no disclosures to declares for this submitted paper

\section{References}

1. Döhner H, Estey E, Grimwade D, Amadori S, Appelbaum FR, Büchner T, et al. Diagnosis and management of AML in adults: 2017 ELN recommendations from an international expert panel. Blood. 2017; 129:424-447.

2. Ferrara F, Schiffer C. Acute myeloid leukaemia in adults. Lancet. 2013; 381:484-495.

3. Fontana L, Strasfeld L. Respiratory virus infections of the stem cell transplant recipient and the hematologic malignancy patient. Infect Dis Clin North Am. 2019; 33:523-544.

4. Pagano L, Salmanton-García J, Marchesi F, Busca A, Corradini P, Hoenigl M, et al. COVID-19 infection in adult patients with hematologic malignancies: a European Hematology Association Survey (EPICOVIDEHA). J Hematol Oncol. 2021; 14(1): 168.

5. Passamonti F, Cattaneo C, Arcaini L, Bruna R, Cavo M, Merli F, et al. Clinical characteristics and risk factors associated with COVID-19 severity in patients with hematological malignancies in Italy: a retrospective, multicentre, cohort study. Lancet Haematol. 2020; 7: e737-e745

6. García-Suárez J, de la Cruz J, Cedillo Á, Llamas P, Duarte R, Jiménez-Yuste V, et al. Impact of hematologic malignancy and type of cancer therapy on COVID-19 severity and mortality: lessons from a large population-based registry study. J

Page $18 / 23$ 
Hematol Oncol. 2020; 13:133.

7. Vijenthira A, Gong IY, Fox TA, Booth S, Cook G, Fattizzo B, et al. Outcomes of patients with hematologic malignancies and COVID-19: a systematic review and meta-analysis of 3377 patients. Blood. 2020; 136:2881-2892.

8. Lee LYW, Cazier JB, Starkey T, Briggs SEW, Arnold R, Bisht V, et al. COVID-19 prevalence and mortality in patients with cancer and the effect of primary tumour subtype and patient demographics: a prospective cohort study. Lancet Oncol 2020; 21:1309-1316.

9. Palanques-Pastor T, Megías-Vericat JE, Martínez P, López Lorenzo JL, Cornago Navascués J, Rodriguez Macias G, et al. Characteristics, clinical outcomes, and risk factors of SARS-COV-2 infection in adult acute myeloid leukemia patients: experience of the PETHEMA group. Leuk Lymphoma. 2021; 62:2928-2938.

10. Fagundes EM, Neto NN, Caldas LM, Aragão JR, Gloria ABF, Leite LG, et al. Mortality by COVID-19 in adults with acute myeloid leukemia: a survey with hematologists in Brazil. Ann Hematol. 2021; Sep 17:1-3. doi: 10.1007/s00277-02104659-w. Online ahead of print.

11. Ghandili S, Pfefferle S, Roedl K, Sonnemann P, Karagiannis P, Boenisch O, et al. Challenges in treatment of patients wit acute leukemia and COVID-19: a series of 12 patients. Blood Adv. 2020;4:5936-5941.

12. Taurino D, Frigeni M, Grassi A, Cavallaro G, Salmoiraghi S, Spinelli O, et al. Concurrent diagnosis of acute myeloid leukemia and symptomatic COVID-19 infection: a case report successfully treated with Azacitidine-Venetoclax combination. Mediterr J Hematol Infect Dis. 2021; 13(1):e2021057.

13. Ferrara F, Zappasodi P, Roncoroni E, Borlenghi E, Rossi G. Impact of COVID-19 on the treatment of acute myeloid leukemia. Leukemia. 2020; 34:2254-2256.

14. Núñez-Torrón C, García-Gutiérrez V, Tenorio-Núñez MC, Moreno-Jiménez G, López-Jiménez FJ, Herrera-Puente P. Poor outcome in patients with acute leukemia on intensive chemotherapy and COVID-19. Bone Marrow Transplant. 2021; 56:267-269.

15. Singh S, Singh J, Paul D, Jain K. Treatment of acute leukemia during COVID-19: focused review of evidence. Clin Lymphoma Myeloma Leuk. 2021; 21:289-294.

16. Demichelis-Gómez R, Alvarado-lbarra M, Vasquez-Chávez J, Delgado-López N, Gómez-Cortés C, Espinosa-Bautista K, et al. Treating Acute Leukemia During the COVID-19 Pandemic in an Environment With Limited Resources: A Multicenter Experience in Four Latin American Countries. JCO Glob Oncol. 2021; 7:577-584.

17. Buyuktas D, Acar K, Sucak G, Toptas T, Kapucu I, Bekoz H, et al. COVID-19 infection in patients with acute leukemia: Istanbul experience. Al J Blood Res. 2021; 11:427-437.

18. Salmanton-García J, Busca A, Cornely OA, Corradini P, Hoenigl M, Klimko N, et al. EPICOVIDEHA: a ready to use platform for epidemiological studies in hematological patients with COVID-19. Hemasphere. 2021; 5(7):e612.

19. Tivian XI GmbH. Experience-management software. https://www.tivian.com/de/. Accessed December 28, 2021.

20. COVID-19 clinical management. Living guidance World Health Organization. January 15, 2021. WHO/2019nCoV/clinical/2021.1.

21. Wu Z, McGoogan JM. Characteristics of and important lessons from the coronavirus disease 2019 (COVID-19) outbreak in China: summary of a report of 72314 cases from the Chinese Center for Disease Control and Prevention. JAMA. 2020; 323:1239-1242.

22. Zeidan AM, Boddu PC, Patnaik MM, Bewersdorf JP, Stahl M, Rampal RK, et al. Special considerations in the management of adult patients with acute leukaemias and myeloid neoplasms in the COVID-19 era: recommendations from a panel of international experts. Lancet Haematol. 2020; 7(8):e601-e612.

23. Raza A, Assal A, Ali AM, Jurcic JG. Rewriting the rules for care of MDS and AML patients in the time of COVID-19. Leuk Res Rep. 2020; 13:100201.

24. Yarza R, Bover M, Paredes D, López-López F, Jara-Casas D, Castelo-Loureiro A, et al. SARS-CoV-2 infection in cancer patients undergoing active treatment: analysis of clinical features and predictive factors for severe respiratory failure

Page $19 / 23$ 
and death. Eur J Cancer. 2020;135:242-250.

25. Ljungman P, de la Camara R, Mikulska M, Tridello G, Aguado B, Zahrani MA, et al. COVID-19 and stem cell transplantation; results from an EBMT and GETH multicenter prospective survey. Leukemia. 2021; 35:2885-2894.

26. Piñana JL, Martino R, García-García I, Parody R, Morales MD, Benzo G, et al. Risk factors and outcome of COVID-19 in patients with hematological malignancies. Exp Hematol Oncol. 2020; 9:21.

27. Stahl M, Narendra V, Jee J, Derkach A, Maloy M, Geyer MB, et al. Neutropenia in adult acute myeloid leukemia patients represents a powerful risk factor for COVID-19 related mortality. Leuk Lymphoma. 2021; 62:1940-1948.

28. Röllig C, Kramer M, Schliemann C, Mikesch JH, Steffen B, Krämer A, et al. Does time from diagnosis to treatment affect the prognosis of patients with newly diagnosed acute myeloid leukemia? Blood. 2020; 136:823-830.

29. Pagano L, Salmanton-García J, Marchesi F, Lopez-Garcia A, Lamure S, Itri F, et al. COVID-19 in vaccinated adult patients with hematological malignancies. Preliminary results from EPICOVIDEHA. Blood. 2021 Nov 8:blood.2021014124. doi: 10.1182/blood.2021014124. Online ahead of print.

\section{Figures}

Figure 1

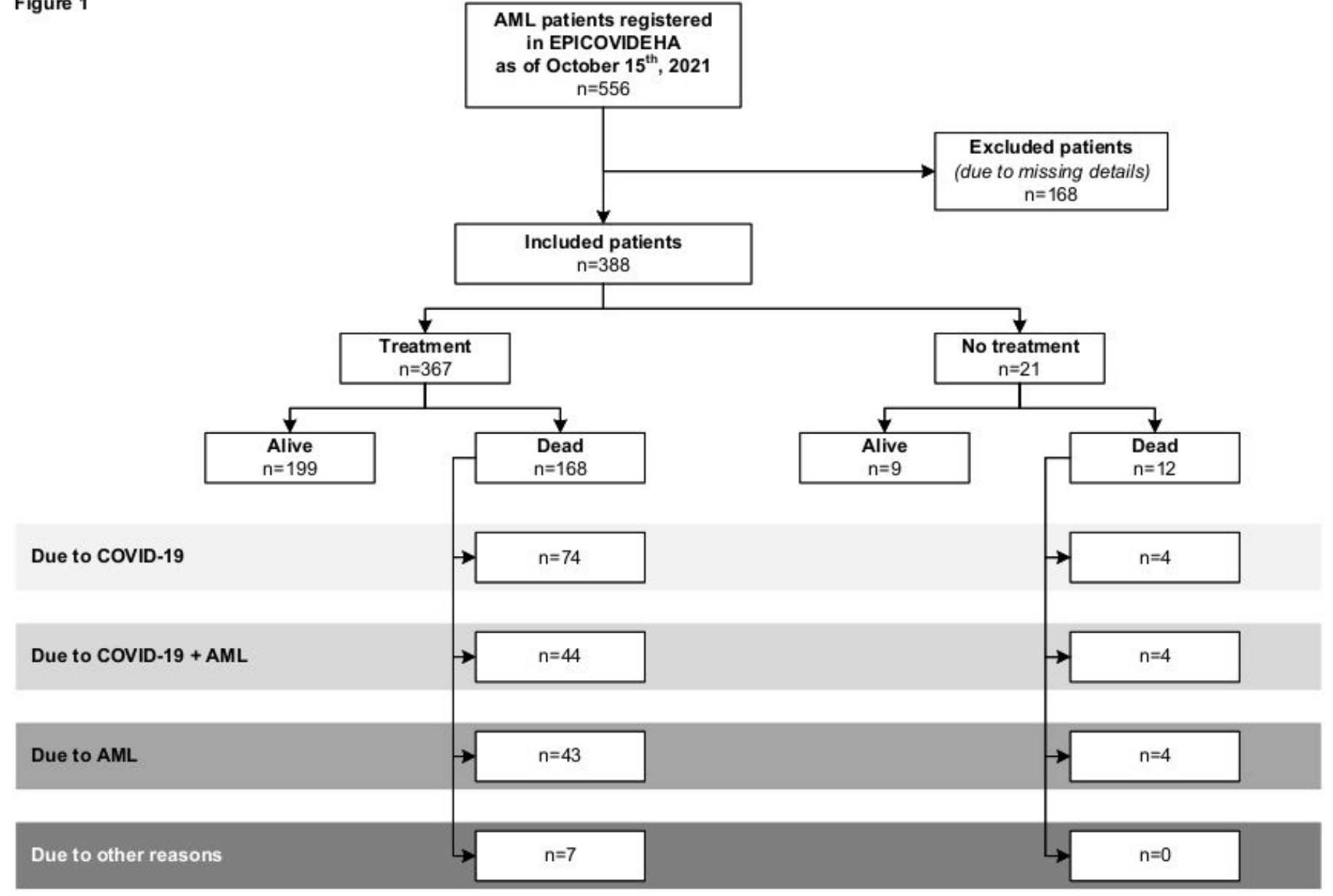

Numbers of Reason(s) for death might be superadditive

AML, acute myeloid leukemia; COVID-19, coronavirus disease 2019; EPICOVIDEHA, COVID-19 study of the European Hematology Association 
Flow-chart of registered AML patients. $\left.{ }^{(}\right)$in 5 patients it’s not known when did they received the treatment; $\left({ }^{\star *}\right)$ number can be super-additive.

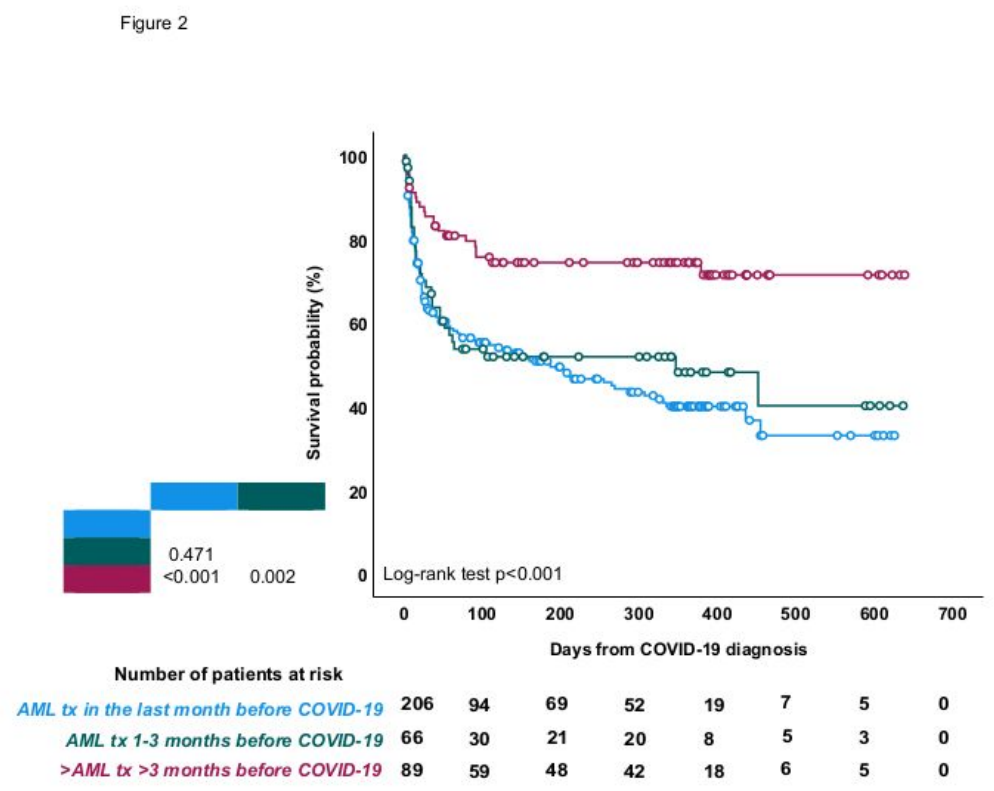

\section{Figure 2}

Overall survival status by timing of last received treatment. 


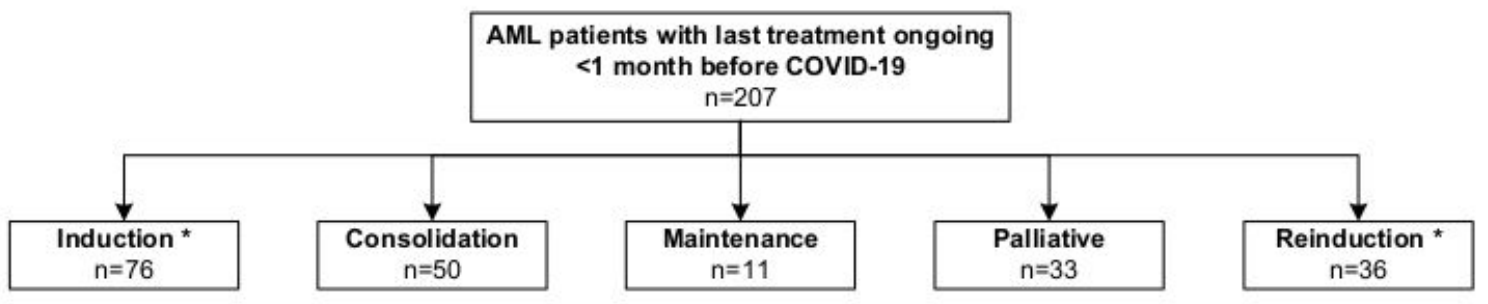

Treatment after COVID-19

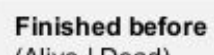
(Alive | Dead)

$$
n=2 \mid 7
$$

$n=12 \mid 0$

$n=1 \mid 5$

$n=2 \mid 8$

$n=4 \mid 9$

\begin{tabular}{|c|c|c|c|c|c|}
\hline $\begin{array}{l}\text { Not delayed } \\
\text { (Alive | Dead) }\end{array}$ & $n=6 \mid 3$ & $n=6 \mid 2$ & $\mathrm{n}=1 \mid 0$ & $n=2 \mid 3$ & $n=0 \mid 1$ \\
\hline
\end{tabular}

Delayed

(Alive | Dead)

$n=13 \mid 3$

$n=12 \mid 2$

$n=4 \mid 0$

$n=7 \mid 0$

$n=4 \mid 4$

\section{Discontinued}

(Alive / Dead)

$n=3 \mid 38$

$n=10 \mid 6$

$n=0 \mid 0$

$n=1 \mid 10$

$n=0 \mid 14$

* In one patient with induction as last chemotherapy strategy, information on treatment continuation after COVID-19 is missing. ** In one patient with no treatment delay, last chemotherapy strategy is unknown. Patients with allogeneic or autologous hematopoietic stem cell transplantation were included in "Reinduction" in this figure.

AML, acute myeloid leukemia; COVID-19, coronavirus diseases 2019

\section{Figure 3}

Treatment modification in AML patients with last treatment on-going $<1$ month before COVID-19. ${ }^{*}$ ) in one patient the last treatment strategy was unknown. 


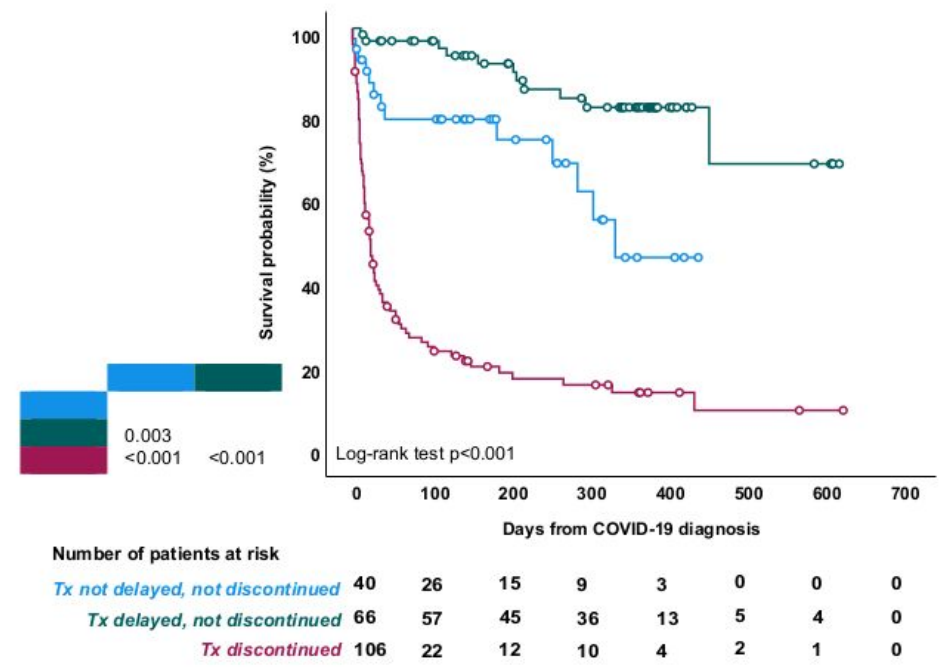

\section{Figure 4}

Overall survival status by modification of initial chemotherapeutic program due to COVID-19 diagnosis.

\section{Supplementary Files}

This is a list of supplementary files associated with this preprint. Click to download.

- FigureS1.OverallsurvivalstatusbymodificationofinitialchemotherapeuticprogramduetoCOVID19diagnosisOnset.pdf

- FigureS2.OverallsurvivalstatusbyobservationtimeJan2020toAug2020vsSept2020toFeb2021vsMar2021toSept2021.pdf 